\title{
Optimization of broadband quantum cascade lasers for continuous wave operation
}

\section{Citation}

Soibel, Alex, Claire Gmachl, Deborah L. Sivco, Milton L. Peabody, A. Michael Sergent, Alfred Y. Cho, and Federico Capasso. 2003. "Optimization of Broadband Quantum Cascade Lasers for Continuous Wave Operation." Applied Physics Letters 83 (1): 24-26. https:// doi.org/10.1063/1.1588374.

\section{Permanent link}

http://nrs.harvard.edu/urn-3:HUL.InstRepos:41371371

\section{Terms of Use}

This article was downloaded from Harvard University's DASH repository, and is made available under the terms and conditions applicable to Other Posted Material, as set forth at http:// nrs.harvard.edu/urn-3:HUL.InstRepos:dash.current.terms-of-use\#LAA

\section{Share Your Story}

The Harvard community has made this article openly available.

Please share how this access benefits you. Submit a story.

Accessibility 


\title{
Optimization of broadband quantum cascade lasers for continuous wave operation
}

\author{
Alex Soibel, ${ }^{\text {a) }}$ Claire Gmachl, Deborah L. Sivco, Milton L. Peabody, A. Michael Sergent, \\ and Alfred Y. Cho \\ Bell Laboratories, Lucent Technologies, 600 Mountain Ave., Murray Hill, New Jersey 07974 \\ Federico Capasso ${ }^{\text {b) }}$ \\ Division of Engineering and Applied Sciences, Harvard University, Cambridge, Massachusetts 02138
}

(Received 3 March 2003; accepted 30 April 2003)

\begin{abstract}
We have optimized the design of the broadband quantum cascade laser for $\mathrm{cw}$ operation. The improved design leads to a gain ripple of only about $4 \mathrm{~cm}^{-1}$ over more than a $0.5-\mu \mathrm{m}$ spectral range. Simultaneous cw emission at several wavelengths spanning the range between 6.7 and 7.4 $\mu \mathrm{m}$ has been achieved in a temperature interval from 20 to $77 \mathrm{~K}$. (C) 2003 American Institute of Physics. [DOI: 10.1063/1.1588374]
\end{abstract}

A broadband quantum cascade (QC) laser emitting in pulsed mode from 6 to $8 \mu \mathrm{m}$ has recently been demonstrated. ${ }^{1}$ The mid-infrared broadband QC laser is expected to be scientifically and technologically important for applications such as chemical and biological sensing. ${ }^{2}$ Due to its broad spectrum, it has potential for the generation of ultrashort pulses by mode-locking. ${ }^{3}$ Self-mode-locking of QC lasers based on the optical Kerr effect has recently been observed. ${ }^{4}$ The pulse width in this experiment was estimated to be of several picoseconds. Pulse generation with broadband QC lasers is expected to shorten the pulse width considerably, to below $1 \mathrm{ps}$.

The previously demonstrated broadband QC laser consists of 36 stages with active regions centered at different emitting wavelengths. ${ }^{1}$ The stages of active regions and injectors were calculated and designed to compensate together for the wavelength dependent losses and to achieve flat net gain over the desired wavelength region. Discrepancies between calculations and experiments were significant and caused considerable variations of the net modal gain across the spectrum that prevented broadband $\mathrm{cw}$ operation of these lasers.

Here, we present a straightforward method for the optimization of the broadband QC laser design. We achieve a small (about $4 \mathrm{~cm}^{-1}$ ) gain ripple across our target wavelength region and demonstrate the broadband $\mathrm{cw}$ operation of QC lasers. These lasers simultaneously emit many modes between 6.7 and $7.4 \mu \mathrm{m}$ at temperature range from 20 to $77 \mathrm{~K}$.

The lasers were grown by molecular-beam epitaxy (MBE) using $\mathrm{In}_{0.53} \mathrm{Ga}_{0.47} \mathrm{As}$ and $\mathrm{Al}_{0.48} \mathrm{In}_{0.52} \mathrm{As}$ lattice matched to InP substrate. The bottom waveguide cladding is formed by the low $n$-type doped $\left(n \sim 2 \times 10^{17} \mathrm{~cm}^{-3}\right) \mathrm{InP}$ substrate. A 600-nm-thick $n$-doped $\left(3 \times 10^{16} \mathrm{~cm}^{-3}\right) \mathrm{InGaAs}$ layer followed by 35 injector-active regions designed for emission at 11 different wavelengths, ${ }^{1}$ and another $400-\mathrm{nm}$ thick $\left(3 \times 10^{16} \mathrm{~cm}^{-3}\right)$ InGaAs layer form the waveguide

\footnotetext{
${ }^{a)}$ Electronic mail: hsasha@lucent.com

${ }^{\text {b)} E l e c t r o n i c ~ m a i l: ~ c a p a s s o @ d e a s . h a r v a r d . e d u ~}$
}

core. The top cladding consists of two $1.5-\mu \mathrm{m}-$ and $800-\mathrm{nm}-$ thick, low-doped $\left(5 \times 10^{16} \mathrm{~cm}^{-3}\right.$ and $1 \times 10^{17} \mathrm{~cm}^{-3}$, respectively) AlInAs layers, followed by a 500-nm-thick highly doped $\left(5 \times 10^{18} \mathrm{~cm}^{-3}\right)$ InGaAs layer, which provides the socalled "plasmon enhanced" optical confinement. ${ }^{5}$

All active regions were chosen to be of the so-called "three-well vertical transition" type ${ }^{6}$ [Fig. 1(a)]. Optical radiation is generated by electrons undergoing intersubband transitions between levels 3 and 2. The wavelength can be varied by changing the thickness of the active region's quantum wells and was designed to decrease monotonically from the bottom to the top, spanning the range from 6.9 to $7.9 \mu \mathrm{m}$ [Fig. 1(b)].

In our first wafer (D2807), we chose the number of active regions centered at any wavelength to be three, except for the "first" and "last" wavelengths, where four stages were grown [Fig. 1(c)]. As we will discuss later in more detail, lasers fabricated from D2807 wafers still exhibited significant variations of modal gain across the desired spectral range. One way to compensate for the observed gain variations would be to redesign the cascade by adjusting the thickness of all quantum wells according to the results of the measurements. However, such an approach is timeconsuming and inefficient due to the difficulties in relating the detailed shape of the observed gain spectrum to the thickness of the wells and barriers. We have demonstrated another, much simpler method, which allowed us to achieve a sufficiently flat gain without additional elaborate efforts to redesign the cascades. In this approach, we have changed the number of emitting active regions at each wavelength according to the measured gain envelope. Explicitly, we have increased the number of the emitting stages at the wavelengths with low gain and have decreased the number of the stages at the spectral regions with high gain. ${ }^{7}$ In the resulting design (wafer D2813), the number of stages is modified from three to two or four, as shown in Figs. 1(b) and 1(c).

The lasers were processed as etched ridges about 10 to $14 \mu \mathrm{m}$ wide and were cleaved to lengths of 3 to $4 \mathrm{~mm}$. The lasers were mounted inside a helium flow cryostat and all measurements were performed at cryogenic temperature ( $T$ $\sim 20 \mathrm{~K}$ ) under an applied dc bias. The optical spectra were 


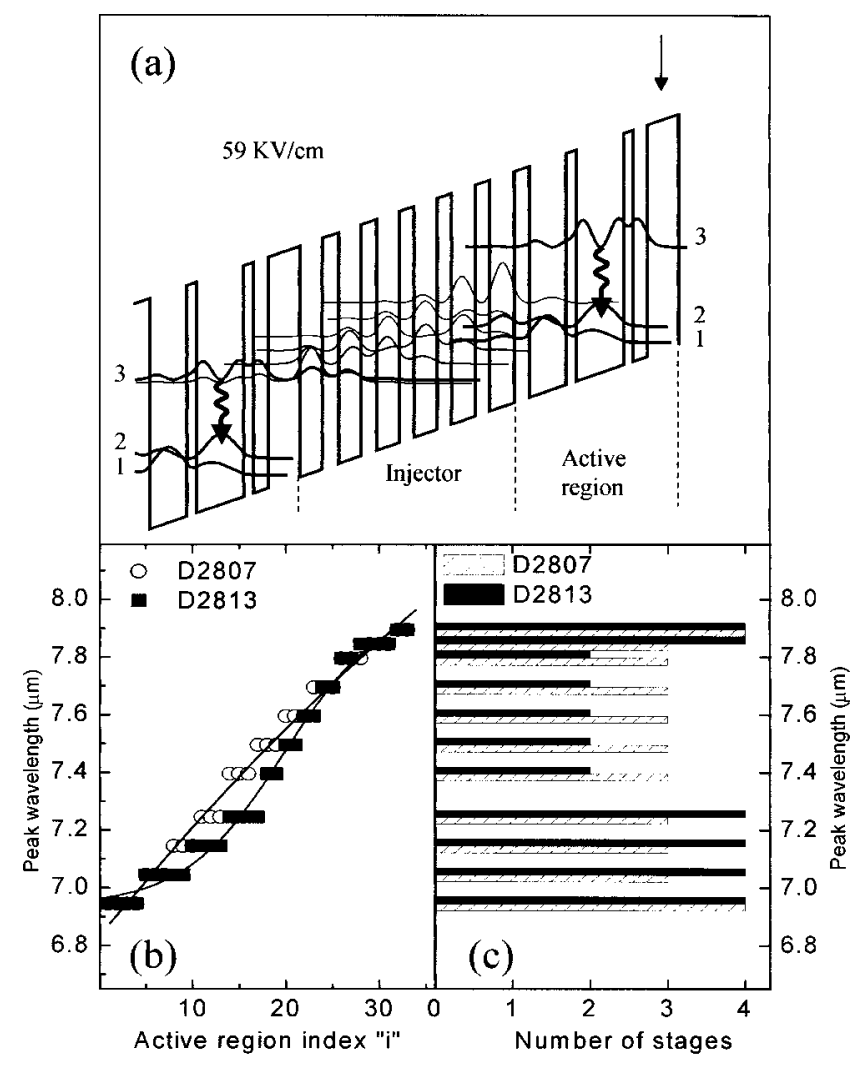

FIG. 1. (a) Conduction band diagram of two active regions designed for the emission at $7.25 \mu \mathrm{m}$ (right) and $7.40 \mu \mathrm{m}$ (left) and the intermediate injector. The layer thickness in $\mathrm{nm}$ from right to left starting from the injection barrier (indicated by an arrow): 4.2/1.9/1.3/6.3/1.4/4.9/2.0/3.3/1.9/3.2/1.9/ 3.1/2.0/3.0/2.1/3.0/2.2/3.0/4.2/2.0/1.3/6.3/1.3/5.0/2.0. AlInAs layers are in bold. The moduli square of the wave functions involved in the laser emission are shown. (b) Calculated peak wavelength versus active region index. (c) The number of active regions centered at each design wavelength versus wavelength. The design central wavelengths of the corresponding active regions are the same for D2807 and D2813 and are offset for clarity.

measured with a Nicolet fast Fourier transform infrared spectrometer and a cooled $\mathrm{HgCdTe}(\mathrm{MCT})$ detector and deuterated triglycine sulfate (DTGS) detector when the laser output power was high.

The inset in Fig. 2 shows subthreshold electroluminescence spectra of lasers D2807 and D2813 operating in cw. The Fabry-Perot fringes are not resolved and appear as dark bands, only interrupted by water vapor absorption lines. The net modal gain can be calculated from the fringe amplitude using the method developed by Hakki and Paoli. ${ }^{8}$ Figure 2 shows the net modal gain of both lasers calculated from the luminescence spectra at a dc bias current close to the threshold. The optimized D2813 wafer has a smoother and more uniformly distributed gain across the targeted spectral region. The gain ripple is about $4 \mathrm{~cm}^{-1}$ in D2813, while the gain ripple is more than $6.5 \mathrm{~cm}^{-1}$ in D2807. The small wavelength shift between the lasers results from unavoidable variations between MBE growth cycles.

The advantages of the more uniform gain of D2813 are explicitly seen in laser operation above threshold. Figure 3 shows the optical spectra of both lasers operating in $\mathrm{cw}$ at different values of operating current. Just above threshold, both lasers are single mode at the position of peak gain. In D2813, a smaller increase of the current by approximately

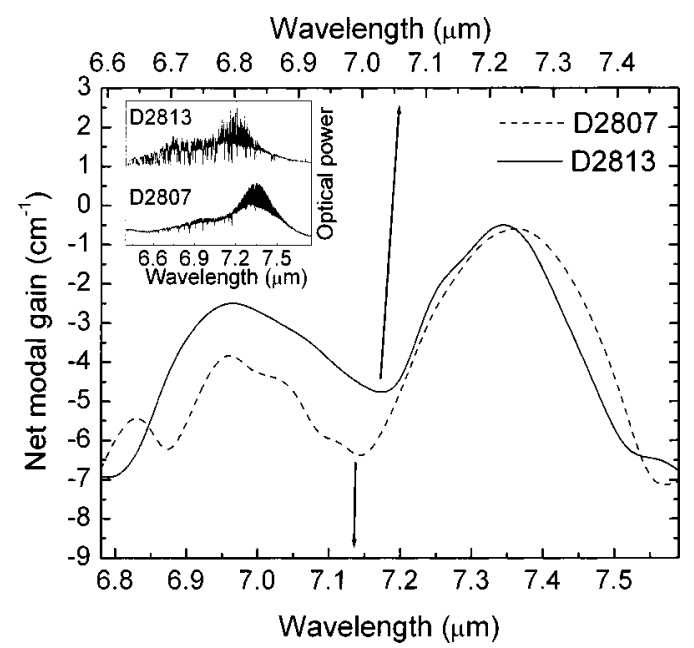

FIG. 2. Net modal gain calculated from the luminescence spectra at a dc current close to threshold, at $I=0.6$ A (D2807) and $I=0.8$ A (D2813), respectively. The $0 \mathrm{~cm}^{-1}$ corresponds to the threshold condition, i.e., when the modal gain (peak material gain $x$ confinement factor) is equal to the optical losses. Inset: Subthreshold electroluminescence spectra of two QC lasers of wafers D2807 and D2813 operating in cw at $T=20 \mathrm{~K}$. The dc current is $I$ $=0.5 \mathrm{~A}$ for laser D2807 (threshold $0.63 \mathrm{~A}$ ) and $I=0.73 \mathrm{~A}$ for laser D2813 (threshold $0.82 \mathrm{~A}$ ). The sharp peaks are caused by water absorption in the air between the laser and the detector.

$20 \%$ to $I=0.85$ A results in the appearance of several additional modes. ${ }^{9}$ As the current is further increased, additional modes appear across the entire gain spectra. At $I=1.2 \mathrm{~A}$, the laser emits 6 modes between 6.7 and $7.4 \mu \mathrm{m}$.

In contrast, D2807 starts to emit multiple modes only when the current is increased by almost $50 \%$ to $1.3 \mathrm{~A}$. However, even at higher current, the lasing modes exist only in part of the gain spectrum. This fact can be clearly seen at $I$ $=1.35 \mathrm{~A}(\mathrm{D} 2807)$ and $I=1.2 \mathrm{~A}(\mathrm{D} 2813)$ in Fig. 3, where the gain is shown in overlap with the laser spectra. In D2807 lasing modes exist only at long wavelengths, while in D2813 lasing modes exist across the entire gain spectrum.

D2813 laser emits broadband up to a maximal temperature about $T=77 \mathrm{~K}$, as shown in Fig. 4. In D2813 the spec-

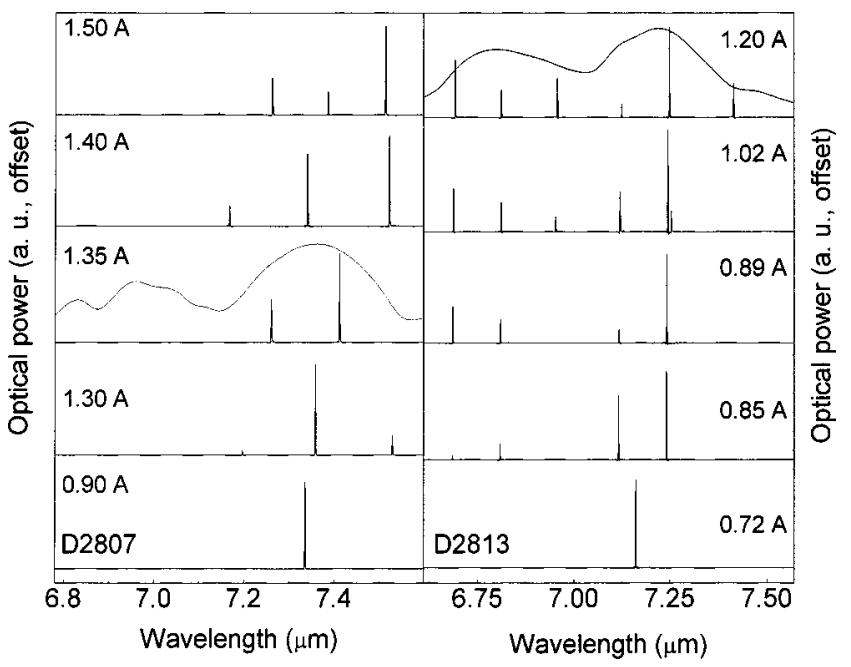

FIG. 3. Laser spectra of D2807 (left) and D2813 (right) operating cw at $T$ $=20 \mathrm{~K}$ at different bias currents. The corresponding gain curves are shown at $I=1.35 \mathrm{~A}(\mathrm{D} 2807)$ and $I=1.2 \mathrm{~A}(\mathrm{D} 2813)$. The latter were calculated from the luminescence spectra near threshold at $I=0.6$ and $I=0.8 \mathrm{~A}$, respectively. 


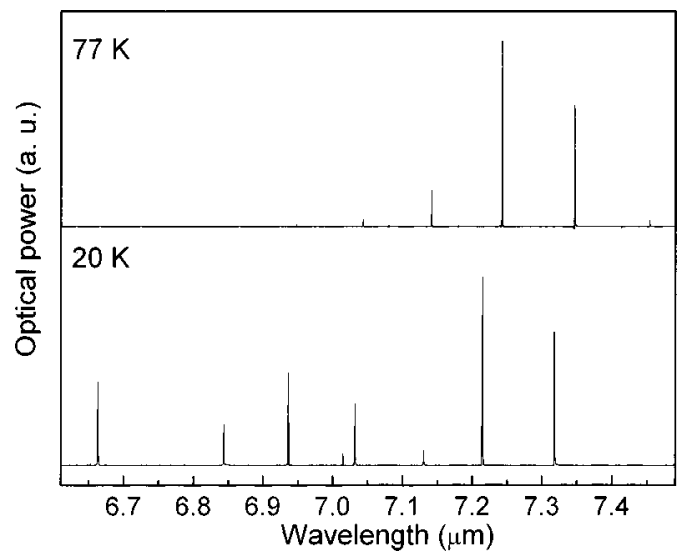

FIG. 4. Optical spectra of a QC laser (D2813) at $I=1.0 \mathrm{~A}$ operating $\mathrm{cw}$ at $T=20 \mathrm{~K}$ (bottom) and $T=77 \mathrm{~K}$ (top).

tral range of optical emission at $T=77 \mathrm{~K}, 7.05-7.35 \mu \mathrm{m}$, is by more than a factor of 2 narrower than that at $T=20 \mathrm{~K}$ and is comparable with the spectral range of the D2807 laser at $T=20 \mathrm{~K}$. The optical spectra of D2813 exhibit a well-known redshift with increasing of the temperature. ${ }^{6}$

The broadband cw QC laser with optimized design discussed in this letter can serve as a single mode source of mid-IR radiation tunable over a wide spectral range when used in conjunction with an external grating. ${ }^{10}$ Such a source is of particular interest for chemical sensing. ${ }^{2}$

This work is supported in part by DARPA/US Army Research Office under Contract No. DAAD 19-00-C-0096.

${ }^{1}$ C. Gmachl, D. L. Sivco, R. Colombelli, F. Capasso, and A. Y. Cho, Nature (London) 415, 883 (2002).

${ }^{2}$ A. A. Kosterev and F. K. Tittel., IEEE J. Quantum Electron. 38, 582 (2002).

${ }^{3}$ Ultrashort Laser Pulses: Generation and Applications, in Topics in Applied Physics Series Vol. 60, edited by W. Kaiser, (Springler, Berlin, 1993).

${ }^{4}$ R. Paiella, F. Capasso, C. Gmachl, D. L. Sivco, J. N. Baillargeon, A. L. Hutchinson, A. Y. Cho, and H. C. Liu, Science 290, 1739 (2000).

${ }^{5}$ C. Sirtori, J. Faist, F. Capasso, D. L. Sivco, A. L. Hutchinson, and A. Y. Cho, Appl. Phys. Lett. 66, 3242 (1995).

${ }^{6}$ J. Faist, F. Capasso, C. Sirtori, D. L. Sivco, J. N. Baillargeon, A. L. Hutchinson, S. G. Chu, and A. Y. Cho, Appl. Phys. Lett. 68, 3680 (1996).

${ }^{7}$ This method cannot perfectly compensate for all variations of the gain. Small variations may possibly be present due to the limited number of the designed wavelengths and digitization of the number of stages centered at each wavelength. The remaining gain variations can be compensated by finer methods, such as change in the doping at different wavelength stages, variation of waveguide losses, etc.

${ }^{8}$ B. W. Hakki and T. L. Paoli, J. Appl. Phys. 46, 1299 (1975).

${ }^{9}$ The increase in the operating current required to excite additional modes slightly varies from device to device.

${ }^{10}$ G. Luo, C. Peng, H. Q. Le, S. Pei, H. Lee, W. Hwang, B. Ishaug, and J. Zheng, IEEE J. Quantum Electron. 38, 486 (2002). 
Applied Physics Letters is copyrighted by the American Institute of Physics (AIP). Redistribution of journal material is subject to the AIP online journal license and/or AIP copyright. For more information, see http:/ojps.aip.org/aplo/aplcr.jsp

Copyright of Applied Physics Letters is the property of American Institute of Physics and its content may not be copied or emailed to multiple sites or posted to a listserv without the copyright holder's express written permission. However, users may print, download, or email articles for individual use. 